\title{
Running head: ROBOT-ASSISTED LINE BISECTION TEST IN VIRTUAL REALITY
}

Robot-assisted line bisection test in virtual reality

Lieve Filbrich, Jean-Jacques Orban de Xivry, Charlotte Verfaille, Philippe Lefèvre, and Valéry Legrain

Université catholique de Louvain, Brussels, Belgium

\section{Author note}

Lieve Filbrich, Institute of Neuroscience, Université catholique de Louvain; JeanJacques Orban de Xivry, Institute of Neuroscience, Université catholique de Louvain \& Institute of Information and Communication Technologies, Electronics and Applied Mathematics, Université catholique de Louvain; Charlotte Verfaille, Institute of Neuroscience, Université catholique de Louvain; Philippe Lefèvre, Institute of Neuroscience, Université catholique de Louvain \& Institute of Information and Communication Technologies, Electronics and Applied Mathematics, Université catholique de Louvain; Valéry Legrain, Institute of Neuroscience, Université catholique de Louvain.

Jean-Jacques Orban de Xivry is now at Movement Control \& Neuroplasticity Research Group and Leuven Brain Institute, KU Leuven.

L.F., C.V. and V.L. are supported by the Fund for Scientific Research of the Frenchspeaking Community of Belgium (F.R.S.-FNRS).

Correspondence concerning this article should be addressed to Lieve Filbrich, Institute of Neuroscience, Université catholique de Louvain, Avenue Mounier 53, COSY boîte B1.53.04, 1200 Brussels, Belgium. E-mail: lieve.filbrich@uclouvain.be 


\begin{abstract}
There is growing evidence in the literature suggesting that sensori-motor deficits have a detrimental impact on cognitive abilities, such as the perception and representation of space. Most of the tasks classically used to assess spatial perception abilities after brain damage seem however not adequate to reveal potentially more discrete impairments in patients that are predominantly suffering from sensori-motor symptoms. To this aim we adapted the classic line bisection task in a virtual reality environment for the use with patients with upper-limb sensory-motor deficits. Here, we report the results from two pre-clinical experiments with healthy volunteers. Lines were projected horizontally on a semi-reflective mirror. Participants were asked to bisect the lines at their estimated midpoint by means of a robotic handle. Manipulated factors were the static hand, the position of the static hand (inside or outside of workspace), the visibility of the hands and the location of the lines. Results showed that participants neglected the most lateral part of the lines when they were projected distantly from the starting point. Bisection biases were in general more important when participants could see their hands. Additionally, participants took more time to initiate movements when they had to cover a short distance to reach the lines. We conclude that our robotic adaptation of the line bisection task was able to highlight subtle perceptual asymmetries in healthy individuals and that its use to reveal discrete cognitive deficits in patients with sensory-motor impairments seems therefore promising.
\end{abstract}

Keywords: spatial perception, line bisection, virtual reality, sensory-motor deficits, neglect 


\section{Introduction}

Perception and representation of space are important abilities for sensori-motor performance and action. To successfully act and interact with our environment we need to correctly perceive and represent the spatial relations between objects or other individuals and our own body, but also between the different objects or individuals themselves.

Even if space is most of the time perceived as a unitary representation, sensory information can be spatially processed according to different frames of reference, which seem to rely on distinct brain and cognitive mechanisms (Halligan, Fink, Marshall, \& Vallar, 2003; Kerkhoff, 2001; Landis, 2000; Previc, 1998). As illustrated above, one traditional distinction is made between egocentric (viewer-centered) and allocentric (object-centered) frames of reference. Another important distinction is made between the personal reference frame (coding the space of the body), the peripersonal reference frame (coding the space immediately surrounding the body where objects are under grasp) and the extrapersonal frame of reference (coding the far space, explored by eyes and limb movements) (Cardinali, Brozzoli, \& Farne, 2009; Previc, 1998; Vallar \& Maravita, 2009). Regarding the body, it is worth noting that, while the notion of personal reference frame is used to characterize topographical processes of somatosensory inputs, it should not be confounded with the concept of body representations that mostly characterize sensori-motor schema, visual description or semantic knowledge of our body (e.g. Schwoebel \& Coslett, 2005).

The importance of the variability of spatial perception abilities is outlined by the fact that consecutively to brain lesions, various and very particular deficits in spatial perception and body representations can be observed (Caramazza \& Hillis, 1990; di Pellegrino, Làdavas, \& Farné, 1997; Guariglia \& Antonucci, 1992; Halligan et al., 2003; Halligan \& Marshall, 1991; Smania \& Aglioti, 1995). For instance, hemispatial neglect can affect different sensory 


\section{ROBOT-ASSISTED LINE BISECTION TEST IN VIRTUAL REALITY}

modalities, as well as the motor domain (separately or concurrently) (Brozzoli, Demattè, Pavani, Frassinetti, \& Farne, 2006; Jacobs, Brozzoli, \& Farne, 2012; Vallar, 1998). Halligan and Marshall (1991), for example, reported a patient with right hemisphere lesions who showed severe visuo-spatial neglect when bisecting lines presented close to the body, but not when lines were presented far away. di Pellegrino et al. (1997) reported a case with tactile but no visual extinction: while the perception of lateralized visual stimuli was correct, the patient was unable to report the perception of a tactile stimulus applied on his contralesional hand when a concurrent tactile stimulus was applied on the opposite hand, and, even more striking, when a visual stimulus was presented near the opposite hand.

However, despite the great disparity of possible spatial deficits, a big part of the screening and assessment methods for spatial perception abilities are focusing on visuo-spatial perception. Indeed, it seems that there is an (implicit) assumption among researchers and clinicians that neglect, for instance, affects mainly the visual domain (Brozzoli et al., 2006) based on the fact that visual manifestations of neglect are supposed to be more outstanding and more easily observed in everyday-life activities than manifestations of other neglect types (Jacobs et al., 2012). Accordingly, impairments in the somatosensory and motor domain seem less investigated. Consecutively, the traditional tasks (e.g. line bisection, copying and drawing, target cancellation) are usually conducted with visual stimuli in external proximal space, without any controlled manipulations of the reference frame involved in the tasks (de Bruin, Bryant, \& Gonzalez, 2014; Hach \& Schutz-Bosbach, 2014; Jacobs et al., 2012; Jacquin-Courtois, Rossetti, Legrain, Sumitani, \& Miyauchi, 2012). One reason could be that, in clinical settings, visual perception is more easily investigated than the other modalities (Jacobs et al., 2012). This issue is particularly illustrated by difficulties in adequately evaluating spatial cognition deficits consecutive to sensori-motor impairments, as for example, in complex regional pain syndrome (CRPS), a chronic pain disorder affecting 


\section{ROBOT-ASSISTED LINE BISECTION TEST IN VIRTUAL REALITY}

usually one limb and characterized by sensory (spontaneous pain, hyperalgesia, allodynia), autonomic (temperature and skin color changes, edema, sweating), trophic (changes in hair/nail growth) and motor symptoms (weakness, tremor, dystonia) (Harden et al., 2010; Marinus et al., 2011). CRPS can indeed also be characterized by cognitive deficits affecting the representation, the perception and the utilization of the affected limb (Legrain, Bultitude, De Paepe, \& Rossetti, 2012). Despite the fact that the similarities between neglect-like symptomatology in CRPS and hemispatial neglect is still a matter of debate (Legrain et al., 2012; Punt, Cooper, Hey, \& Johnson, 2013), various symptoms were described such as asomatognosia, hypo- and bradykinesia, impaired mental image and schema of the affected limb, tactile allesthesia and synchiria, and biased judgment of the temporal order of tactile stimuli (e.g. Forderreuther, Sailer, \& Straube, 2004; Galer, Butler, \& Jensen, 1995; Galer \& Jensen, 1999; Lewis, Kersten, McCabe, McPherson, \& Blake, 2007; McCabe, Haigh, Halligan, \& Blake, 2003; Moseley, 2004, 2005; Moseley, Gallace, \& Spence, 2009; Schwoebel, Friedman, Duda, \& Coslett, 2001). However, neglect-like symptomatology in CRPS could not been evidenced by classical neuropsychological testing (Christophe et al., 2016; Forderreuther et al., 2004; Kolb, Lang, Seifert, \& Maihofner, 2012; Reid et al., 2016; Reinersmann et al., 2012) and visuo-spatial abnormalities have only been demonstrated in very specific experimental testing conditions. For instance, Sumitani, Shibata, et al. (2007) observed difficulties in judging the position of a visual stimulus according to their own body midline in CRPS patients. Similarly, Filbrich et al. (2017) and Bultitude, Walker, and Spence (2017) observed that patients with upper-limb CRPS tend to bias the perception of visual stimuli to the detriment of stimuli presented close to their pathological hand while performing temporal order judgements. In the same manner, it was shown that the complete ablation of one limb can affect the perception of visual stimuli, mainly when presented close to the body, addressing the question of neglect-like symptoms after amputation (Makin, Wilf, Schwartz, \& 
Zohary, 2010). These examples illustrate that the representation and perception of the body and space are shaped by sensori-motor experiences (see also Dupierrix, Alleysson, Ohlmann, and Chokron (2008), Dupierrix, Gresty, Ohlmann, and Chokron (2009) and Michel et al. (2003) for a demonstration of the influence of lateralized sensori-motor experience on biased space perception in healthy participants). Even more, these data suggest that sensori-motor deficits can produce important changes in cortical plasticity resulting in complex cognitive deficits such as unbalanced perception and exploration of space.

A close relationship between sensori-motor and perceptual deficits seems thus to be of importance in several disorders, but assessment and rehabilitation approaches often seem to focus mainly on either one of the two symptomatologies - e.g. perceptual manifestations in brain-damaged hemineglect patients and sensori-motor symptoms in disorders like CRPS for example. A more multimodal-based approach could however have potentially important implications for the effectiveness of rehabilitation. There is thus clearly a need to develop tools able to assess patients' capacities to perceive and explore the space of the body with an emphasis on visuo-motor coordination.

To this aim we adapted the line bisection task, classically used in its paper-and-pencil version, for the use in a robotic virtual environment. Line bisection tasks are widely used when screening for neglect in brain-damaged patients and spatial perception abilities in healthy individuals. However, these paper-and-pencil versions are not always sensitive enough and not always suited to quantify the degree of impairment or imbalance (Azouvi et al., 2002; Bonato, 2012). Another shortcoming of these tasks is that they are usually not able to dissociate between perceptual and motor aspects of neglect (Harvey, 2004; Husain, Mattingley, Rorden, Kennard, \& Driver, 2000). They are mainly informative about visual aspects and the space outside the body (see above). Furthermore, paper-and-pencil tasks are usually static and there is no flexibility in presentation from one testing session to the next. 
This can lead to learning and compensation effects, with subsequent ceiling effects and normalization of performance, even when patients still present difficulties in everyday-life situations (Bonato \& Deouell, 2013).

Recently, the field of cognitive neuroscience saw the development of more computerized and virtual reality tools to adapt classic paper-and-pencil evaluation tasks, including those assessing neglect consecutive to brain damage (Baheux, Yoshizawa, Seki, \& Handa, 2006; Fordell, Bodin, Bucht, \& Malm, 2011; Tsirlin, Dupierrix, Chokron, Coquillart, \& Ohlmann, 2009; Vaes et al., 2014) or for experimental use with healthy participants (Gamberini, Seraglia, \& Priftis, 2008; Heber, Siebertz, Wolter, Kuhlen, \& Fimm, 2010). These tools have the advantage that they allow to finely control the testing environment and to improve the ecological value of the tasks. They can highlight more subtle asymmetries or impairments and provide more insight on how a participant is executing the task, by facilitating the manipulation of behavioral responses and more precise and detailed recordings of the dependent variables. Contrary to most of the classic paper-and-pencil tasks they could also be used to dissociate perceptual and motor manifestations of neglect (Bisiach, Geminiani, Berti, \& Rusconi, 1990; Harvey, 2004; Husain et al., 2000). Besides being potentially more sensitive, these tools raise the possibility for a qualitative and quantitative assessment approach. Furthermore, flexible variation of stimulus presentation and task difficulty allow reducing ceiling effects and makes it more difficult to develop compensation strategies. They facilitate a more standardized and repeatable assessment of neglect symptoms. Because they simulate real and interactive environments and situations, virtual reality and computerized tools can also potentially be of great interest in the rehabilitation of patients suffering from spatial perception disabilities (Rose, Brooks, \& Rizzo, 2005; Tsirlin et al., 2009; Vaes et al., 2014). 
Our aim was to develop a measure of spatial perception abilities in a controlled and interactive visuo-spatial environment in which the space of the body (i.e. an affected body part) and visuo-motor coordination can be taken into account. One important feature of the task is that it can control the spatial projection of visual stimuli relative to the personal (i.e. the body) and peripersonal space in the vicinity of the body, as well as the potential influence of the presence vs. absence of the hand inside the workspace. It is well known in the literature that bisection biases can vary as function of stimulus properties, e.g. their location relative to the participants' body (Jewell \& McCourt, 2000). In the present study we tested if and how manipulated parameters like the presence of the body and the spatial location of visual stimuli can affect spatial perception and action in healthy participants, with the aim to adapt this task for the use with patients suffering from upper-limb sensori-motor impairments. Insights about the cognitive mechanisms of space and body representations in healthy individuals are important for the understanding and the further study of disorders thought to affect these representations.

\section{Experiment 1}

\section{Participants}

Ten participants ( 7 females, $M=29.6$ years, $\mathrm{SD}=2.72$, range: $26-34$ years) volunteered to take part in the experiment. All participants had at least 17 years of education. Inclusion criteria were normal or corrected-to-normal vision, no neurological or psychiatric antecedents, and no current use of psychotropic drugs. According to the Flinders Handedness Survey (Flanders) (Nicholls, Thomas, Loetscher, \& Grimshaw, 2013), all but one of the participants were right-handed. Experimental procedures were approved by the Ethics Committee of the Université catholique de Louvain and conform to the Declaration of Helsinki. All participants provided written informed consent to participate in the study.

\section{Stimuli and apparatus}


The experiment was conducted by means of the robotic system KINARM ${ }^{\mathrm{TM}}$ (BKIN Technologies, Kingston, ON, Canada) (see Figure 1). The KINARM is made up of two systems. First, a robotic section that comprises two graspable handles and allows the encoding of various movement-related parameters such as position coordinates and speed. Second, placed just above the robotic section, a virtual reality system that is made up of a horizontal semi-reflection mirrored screen. This device allows combining direct observation of the robotic section and reflection of visual stimuli projected from a horizontal monitor at the top of the device. In the present task, participants controlled one of the two robotic handles in order to move a cursor displayed on the semi-reflective mirror placed above the handles. Visual stimuli were horizontally presented orange lines which were projected on one of the hemi-spaces ( $35 \mathrm{~cm}$ long and $34 \mathrm{~cm}$ wide) of the semi-reflective mirror. The lines could be of three different lengths: 20, 15 and $10 \mathrm{~cm}$. Each line was $0.3 \mathrm{~cm}$ thick. They were projected at a distance of $10 \mathrm{~cm}$ in depth with regard to the proximal segment of the mirror, and according to three different locations: the center of the lines was situated at a distance of 0 (medial), 11.25 (intermediate), or $22.5 \mathrm{~cm}$ (lateral) of the median vertical of the mirror (see Figure 2).

\section{Procedure}

The participants were seated in front of the mirror so that the sagittal median line of their bodies extended the median vertical of the mirror. A forehead rest was used to keep the distance between the eyes and the lines as constant as possible and to minimize deviations to one side of the workspace. The experiment consisted of 8 blocks of line projections. During each block, the projection of the lines of each length at each location was repeated 6 times (3 line lengths $* 3$ line locations $* 6$ repetitions $=54$ lines per block). One hand (the left one in half of the blocks and the right one in the other half) was placed under one of the hemi-spaces of the mirror (static hand). During half of the blocks (hand inside condition), the static hand was placed in the workspace, below the location where the most lateral line with regard to the 


\section{ROBOT-ASSISTED LINE BISECTION TEST IN VIRTUAL REALITY}

median of the mirror (at $22.5 \mathrm{~cm}$ ) was projected. More precisely, there was a mark on the table which was shifted horizontally by $8 \mathrm{~cm}$ (more laterally) and vertically by $2 \mathrm{~cm}$ (more deeply) regarding to the midpoint of the lateral lines. The articulation between the metacarpus and the proximal phalanx of the little finger was placed on this mark, so that the participants had the illusion that the lateral lines were projected on their hand. During the other half of the blocks (hand outside condition), the static hand was placed at a more external position, outside the workspace. Vision of the workspace through the mirror and thus of the hands was either provided in half of the blocks (hands visible condition), or precluded in the other half of the blocks (hands invisible condition), by closing a store just underneath the mirror (see Figure 1B). The participants had to grab the contralateral handle of the robot with their other hand (the active hand). The position of the handle on the mirror was marked by a cursor in form of a plain white circle ( $7 \mathrm{~mm}$ diameter). For half of the participants the first four blocks were realized with the left hand as active hand (in the right hemi-space of the semi-reflective mirror) and the following four blocks with the right hand as active hand (in the left hemispace of the semi-reflective mirror). This order was reversed for the other half of the participants. Each block of the experiment was defined by one of the four possible combinations of the factors static hand position and vision (hand inside and visible, hand inside and invisible, hand outside and visible, hand outside and invisible) (see Figure 3). The order of the four blocks was randomly determined and reversed on the occasion of the hand switching. Each trial started with the appearance of a yellow square $(2 \mathrm{~cm}$ sides $)$ at a distance of $10 \mathrm{~cm}$ underneath the location of the projected lines (in depth) and a distance of $-5 \mathrm{~cm}$ regarding the median of the mirror (a negative value implied that the yellow square appeared on the hemi-space contralateral to the one the static hand was placed in). The participants were asked to grab the handle with their active hand and position the cursor inside the yellow square. When the cursor was in position, a line was projected on the mirror and the participant 
had to bisect the line at its estimated midpoint. The yellow square disappeared as soon as the cursor was moved out of it. The participant had to perform the bisection in one smooth movement and the trial ended as soon as the cursor crossed the line. The next trial started 400 ms later. One block took approximately four minutes.

\section{Measures}

For each condition, two measures were taken. The first measure was the bisection bias, which was calculated for each line by subtracting the coordinate of the point where the participant bisected the line from the coordinate of the true midpoint. A positive value indicated a bias towards the left side and a negative value a bias to the right side. To match the measures of the lines projected in the right and the left hemi-spaces of the workspace, bisection indexes for right-sided lines were multiplied by -1 , so that a positive value indicated a bias towards the outside of the workspace and a negative value a bias towards the inside of the workspace. Finally bisection biases were transformed proportionally to the length of the lines and expressed in percentages. The second measure was the movement initiation time, which was computed as the time difference between the emergence of the line and the onset of movement. Onset of movement was defined as the moment when the hand (the cursor) left the yellow square starting position and hand velocity was higher than $0.02 \mathrm{~m} / \mathrm{s}$ (Orban de Xivry, 2013)

\section{Data analysis}

One sample t-tests were performed to test if bisection biases were significantly different from zero.

To analyze the measures bisection bias and movement initiation time repeated measures analysis of variance (ANOVA) was performed with static hand (left vs. right), vision (visible vs. invisible), static hand position (inside vs. outside of workspace) and line 
location (medial $[0 \mathrm{~cm}]$ vs. intermediate $[11.25 \mathrm{~cm}]$ vs. lateral $[22.5 \mathrm{~cm}]$ ) as withinparticipant factors. Data from the variable line length was merged because it was not relevant to our research questions - it was originally introduced to diversify the task and to avoid that participants adopt strategies in performance. Contrast analyses were performed when needed. Significance level was set at $\mathrm{p}=.050$.

\section{Results}

Bisection bias. Bisection biases are illustrated in Figure 4. When participants worked in the left hemi-space (left hand static condition), one sample t-tests revealed a right-ward bisection bias (to the inside of the workspace) significantly different from zero in the hands visible condition at the lateral line location. This was the case for the static hand inside as well as the static hand outside position (all $t>-3.100, p \leq .013, d>.98$ ). When participants worked in the right hemi-space (right hand static condition), one sample t-tests revealed only a trend towards a left-ward bisection bias (to the inside of the workspace) significantly different from zero in the hands visible condition at the lateral line location when the static hand was placed inside the workspace $(t(9)=-2.253, p=.051, d=.71)$.

The four-way ANOVA with the factors static hand, vision, static hand position and line location revealed significant main effects of vision $\left(F(1,9)=8.371, p=.018, \eta^{2} p=.482\right)$ and of line location $\left(F(2,18)=6.144, p=.009, \prod^{2} \mathrm{p}=.406\right)$. None of the other main effects or interactions was significant (all $F \leq .982$, all $p \geq .348$ ).

The significant main effect of vision suggests that bisection biases were greater when the hands were visible $\left(\mathrm{M}_{\text {deviation }}=-1.1 \%, \mathrm{SD}=1.8 \%\right)$ than when they were invisible $\left(\mathrm{M}_{\text {deviation }}=-\right.$ $0.2 \%, \mathrm{SD}=1.5 \%)\left(\mathrm{M}_{\text {difference }}=0.9 \%, 95 \%\right.$ CI $\left.[0.2,1.6]\right)$. As for the main effect of line location, follow-up analyses revealed a significant difference between medial and lateral line locations $\left(F(1,9)=5.999, p=.037, \eta^{2} \mathrm{p}=.400\right)$ and between intermediate and lateral line locations $\left(F(1,9)=8.849, p=.016, \eta^{2} \mathrm{p}=.496\right)$. These results suggest that bisection biases are 
greater at the lateral line location $\left(\mathrm{M}_{\text {deviation }}=-1.8 \%, \mathrm{SD}=2.3 \%\right)$ than at the medial $\left(\mathrm{M}_{\text {deviation }}\right.$ $=-0.3 \%, \mathrm{SD}=0.9)\left(\mathrm{M}_{\text {difference }}=1.6 \%, 95 \% \mathrm{CI}[0.1,3]\right)$ and the intermediate line location $\left(\mathrm{M}_{\text {deviation }}=0 \%, \mathrm{SD}=2.1 \%\right)\left(\mathrm{M}_{\text {difference }}=1.8 \%, 95 \% \mathrm{CI}[0.4,3.2]\right)$. There was no significant difference when comparing the medial to the intermediate line location $(F(1,9)=.414$, $\left.p=.536, \prod^{2} \mathrm{p}=.044\right)\left(\mathrm{M}_{\text {difference }}=0,3 \%, 95 \%\right.$ CI $\left.[-1.2,0.7]\right)$.

Movement initiation time. The four-way ANOVA revealed only a significant main effect of line location $\left(F(1.088,9.788)=27.987, p<.001, \eta^{2} p=.757\right)$. None of the other main effects or interactions was significant (all $F \leq|2.027|$, all $p \geq .188$ ). Follow-up analyses revealed a significant difference between medial and intermediate line locations $(F(1,9)=$ $\left.30.485, p<.001, \eta^{2} p=.772\right)$ and between medial and lateral line locations $(F(1,9)=27.380$, $p=.001, \eta^{2} p=.753$ ). These results suggest that participants took significantly more time to initiate movements towards the lines projected at the medial location $(\mathrm{M}=395.024 \mathrm{~ms}, \mathrm{SD}=$ $61.126 \mathrm{~ms})$ than at the intermediate $(\mathrm{M}=334.965 \mathrm{~ms}, \mathrm{SD}=39.110 \mathrm{~ms})\left(\mathrm{M}_{\text {difference }}=60.059\right.$, $95 \%$ CI $[35.452,84.666])$ and lateral $(M=334.737 \mathrm{~ms}, \mathrm{SD}=35.042 \mathrm{~ms})\left(\mathrm{M}_{\text {difference }}=60.287\right.$, 95\% CI [34.224, 86.351]) locations. There was no significant difference between the intermediate and the lateral line location $\left(F(1,9)=.007, p=.936, \eta^{2} \mathrm{p}=.001\right)\left(\mathrm{M}_{\text {difference }}=\right.$ $0.228,95 \%$ CI $[-6.043,6.5])$ (see Figure 5).

\section{Discussion}

The results of this first study suggest that healthy participants present a significant bisection bias to the inside of the workspace when they have to bisect lines at the lateral location. In other words, participants presented a right-ward bias when working in the left hemi-space, but a left-ward bias when working in the right hemi-space. Whether this bisection bias for lines at a lateral location is due to the fact that they were the most distant from the body midline or to the fact that the distance to cover was the longest could however not be determined. In general, biases seem to be significantly greater when participants can see their 
hands as compared to the condition when they can't see their hands. Regarding the movement initiation time, participants took more time to initiate movements towards the lines projected at the medial location than to the intermediate and lateral locations. Again, this result raises the question if movement initiation was slower because the medial lines are close to the body or because they are close to the starting point.

To address these questions we designed a second experiment in which we added a condition where the lines the closest do the body midline were also the lines the furthest from the starting point. The factors static hand and static hand position were not included as such in this second study.

\section{Experiment 2}

\section{Participants}

Ten participants (5 females, $M=30.3$ years, SD $=11.06$, range: $18-60$ years) volunteered to take part in this experiment. All participants had at least 12 years of education. Inclusion criteria were the same as in Experiment 1. According to the Flinders Handedness Survey (Flanders) (Nicholls, Thomas, Loetscher, \& Grimshaw, 2013), eight participants were right-handed and two participants ambidextrous. Experimental procedures were approved by the Ethics Committee of the Université catholique de Louvain and conform to the Declaration of Helsinki. All participants provided written informed consent to participate in the study.

\section{Stimuli and apparatus}

The experimental set-up and stimuli were similar to the first experiment. The same lengths and locations were used for the lines, with the exception that line location was defined according to the distance of the movement from the starting point to the line. Each line was repeated ten times during each block, resulting in 90 lines per block (3 line lengths*3 
distances of movement*10 repetitions). The experiment consisted of 6 blocks, that is, 540 presented lines.

\section{Procedure}

The experimental procedure was similar to the one used in Experiment 1. There were however three different experimental conditions, depending on the combination of the hemispace in which the lines were projected (left or right) and the position of the static hand (central or distant). In a first condition, the lines were projected in the left hemi-space of the mirror and the left hand (static hand) was placed also on the left, below the location where the most lateral line with regard to the median of the mirror (at $22.5 \mathrm{~cm}$ ) was projected (left/distant). The starting position (yellow square) was situated at a distance of $10 \mathrm{~cm}$ underneath the location of the projected lines (in depth) and a distance of $-5 \mathrm{~cm}$ regarding the median of the mirror (in the right hemi-space). Participants were thus working in the left hemi-space, and the static left hand was placed within that workspace. In a second condition, the lines were projected in the right hemi-space of the mirror, but the left hand remained placed in the same position than in the first condition, that is, in the left hemi-space (right/distant). The starting square appeared at a distance of $10 \mathrm{~cm}$ underneath the location of the projected lines (in depth) and a distance of $-27.5 \mathrm{~cm}$ regarding the median of the mirror. Participants were thus working in the right hemi-space, and the static left hand was placed outside that workspace. In a third condition, lines were projected in the right hemi-space of the mirror and the starting square appeared at a distance of $10 \mathrm{~cm}$ underneath the location of the projected lines (in depth) and a distance of $-27.5 \mathrm{~cm}$ regarding the median of the mirror. In the present condition, the left hand was moved at a more central position, below the location where the most medial line with regard to the median of the mirror $($ at $0 \mathrm{~cm})$ was projected (right/central). As in Experiment 1, vision of the workspace through the mirror and thus of the hands was either provided (hands visible), or precluded (hands invisible). The right 
hand was always used as active hand. Participants had to grab the left handle of the robot in the first condition and the right handle in the second and the third condition. The six blocks of the experiment were defined by different combinations of the three experimental conditions and the factor vision (left/distant and visible, left/distant and invisible, right/distant and visible, right/distant and invisible, right/central and visible, right/central and invisible) (see Figure 6). Block order was randomly determined for each participant. The experiment took approximately 40 minutes (i.e. 5-6 minutes per block).

\section{Measures}

As in Experiment 1, the two dependent measures were the bisection bias and movement initiation time. Because participants always used their right hand as active hand, bisection indexes for right and left-sided lines didn't have to be matched. A positive value indicated a bias towards the left side, and a negative value a bias towards the right side. As in the first experiment, bisection biases were transformed proportionally to the length of the lines and expressed in percentages.

\section{Data analysis}

One sample t-tests were performed to test if bisection biases were significantly different from zero.

Repeated measures analysis of variance (ANOVA) was performed with position of the lines and of the static hand (left/distant vs. right/distant vs. right/central), vision (visible vs. invisible) and distance of movement (short [0 cm] vs. intermediate $[11.25 \mathrm{~cm}]$ vs. long [22.5 $\mathrm{cm}]$ ) as within-participant factors. As in Experiment 1, data from the variable line length was merged.

Finally, a second ANOVA was performed, but only on bisection biases for the lines whose center was situated at a distance of $0 \mathrm{~cm}$ with regard to the median vertical of the 
mirror. These lines were located at exactly the same location across the three conditions; the location of the lines relative to the median vertical of the mirror was therefore controlled when estimating the effect of position and distance of movement. A two-way ANOVA was used with the factor vision and the new factor position. The factor position comprises three variables: short distance of movement, left hand at a distant position (short/distant), long distance of movement, left hand at a distant position (long/distant), long distance of movement, left hand at central position (long/central).

Contrast analyses were performed when needed using partial ANOVAS and paired ttests. Significance level was set at $\mathrm{p}=.050$.

\section{Results}

Bisection bias. Bisection biases are shown in Figure 7. At the left/distant position, one sample t-tests revealed right-ward bisection biases significantly different from 0 for the long distances of movement when the hands were visible $(t(9)=-4.406, p=.002, d=1.39)$. In the visible condition, right-ward biases were also significant at the intermediate distance of movement $(t(9)=-3.161, p=.035, d=.78)$. When the hands were invisible, right-ward biases only approached significance at the long distance of movement $(t(9)=-2.209, p=.055, d=$ .70). In the right/distant position, one sample t-tests revealed also significant right-ward bisection biases at the long distance of movement in the visible condition $(t(9)=-3.243, p=$ $.010, d=1.02$ ). In the visible condition, significant right-ward biases were also observed at the intermediate distance of movement, $(t(9)=-2.387, p=.041, d=.75)$. In the invisible condition however, analyses revealed left-ward biases at the short distance of movement $(t(9)$ $=3.384, p=.008, d=1.1)$. Analyses in the right/central position revealed the same results as in the previous condition: right-ward biases at the long $(t(9)=-3.534, p=.006, d=1.1)$ and the intermediate $(t(9)=-2.473, p=.035, d=.78)$ distance of movement in the visible condition, but left-ward biases at the short distance of movement in the invisible condition 
$(t(9)=3.355, p=.008, d=1.1)$. Right-ward bisection biases at the long distance of movement in the invisible condition approached significance $(t(9)=-2.212, p=.054, d=.70)$

The three-way ANOVA revealed significant main effects of vision $(F(1,9)=18.764$, $\left.p=.002, \prod^{2} \mathrm{p}=.676\right)$ and of distance of movement $\left(F(2,18)=10.702, p=.001, \prod^{2} \mathrm{p}=.543\right)$. None of the other main effects or interactions was significant (all $F<2.508$, all $p \geq .106$ ). The significant main effect of vision suggests that bisection biases were greater when the hands were visible $\left(\mathrm{M}_{\text {deviation }}=-3.4 \%, \mathrm{SD}=3.5 \%\right)$ than when they were invisible $\left(\mathrm{M}_{\text {deviation }}=-\right.$ $1.7 \%, \mathrm{SD}=3.7 \%)\left(\mathrm{M}_{\text {difference }}=1.7 \%, 95 \% \mathrm{CI}[0.8,2.6]\right)$. As for the main effect of distance of movement, follow-up analyses revealed a significant difference between the short and the intermediate $\left(F(1,9)=8.755, p=.016, \eta^{2} \mathrm{p}=.493\right)$ and between the short and the long $(F(1,9)$ $\left.=14.248, p=.004, \eta^{2} \mathrm{p}=.613\right)$ distance of movement. These results suggest that bisection biases were significantly smaller at the short distance of movement $\left(\mathrm{M}_{\text {deviation }}=0 \%, \mathrm{SD}=\right.$ $1.6 \%)$ than at the intermediate $\left(\mathrm{M}_{\text {deviation }}=-3.3 \%, \mathrm{SD}=4.8 \%\right)\left(\mathrm{M}_{\text {difference }}=3.3 \%, 95 \% \mathrm{CI}[0.8\right.$, $5.8])$ and at the long distance of movement $\left(\mathrm{M}_{\text {deviation }}=-4.5 \%, \mathrm{SD}=4.6 \%\right)\left(\mathrm{M}_{\text {difference }}=4.5 \%\right.$, 95\% CI $[1.8,7.2])$. There was no significant difference between the intermediate and the long distance of movement $\left(F(1,9)=3.813, p=.083, \eta^{2} \mathrm{p}=.298\right)\left(\mathrm{M}_{\text {difference }}=1.2 \%, 95 \%\right.$ CI $[-0.2$, 2.6]).

Finally, the two-way ANOVA with the factors position (the combination of the distance of movement and position of the static hand) and vision, which was only performed on bisection biases for the lines whose center was situated at a distance of $0 \mathrm{~cm}$ with regard to the median vertical of the mirror, revealed a main effect of position $(F(2,18)=8.903, p=$ $.002, \eta^{2} \mathrm{p}=.497$ ). None of the other main effects or interactions was significant (all $F<$ |4.144|, all $p \geq .072$ ). Follow-up analyses showed that bisection biases were smaller at a short distance of movement in the distant hand position $\left(\mathrm{M}_{\text {deviation }}=-1.2 \%, \mathrm{SD}=3.1 \%\right)$ than, respectively, at a long distance of movement in the distant hand position $\left(\mathrm{M}_{\text {deviation }}=-4 \%, \mathrm{SD}\right.$ 
$=4.8 \%)\left(F(1,9)=13.025, p=.006,95 \%\right.$ CI $\left.[1.1,4.6], \prod^{2} p=.591\right)$ and the central hand position $\left(\mathrm{M}_{\text {deviation }}=-4.3 \%, \mathrm{SD}=4.6 \%\right)\left(F(1,9)=11.046, p=.009,95 \%\right.$ CI $[1,5.3], \Pi^{2} \mathrm{p}=$ .551). The difference between the two latter conditions was not significant $(F(1,9)=0.200, p$ $\left.=.665, \eta^{2} \mathrm{p}=.022\right)\left(\mathrm{M}_{\text {difference }}=0.3 \%, 95 \% \mathrm{CI}[-1.9,1.3]\right)$.

Movement initiation time. The three-way ANOVA revealed only a significant main effect of the factor distance of movement $\left(F(1.079,9.708)=29.224, p<.001, \prod^{2} p=.765\right)$. None of the other main effects or interactions was significant (all $F<|2.489|$, all $p \geq .124$ ). Follow-up analyses revealed a significant difference between short and intermediate distances of movement $\left(F(1,9)=39.535, p<.001, \eta^{2} \mathrm{p}=.815\right)$ and between short and long distances of movement $\left(F(1,9)=26.770, p=.001, \eta^{2} \mathrm{p}=.748\right)$. These results suggest that participants took significantly more time to initiate movements when they had to cover a short distance $(\mathrm{M}=334.513 \mathrm{~ms}, \mathrm{SD}=41,053 \mathrm{~ms})$ as compared to an intermediate $(\mathrm{M}=293.302 \mathrm{~ms}, \mathrm{SD}=$ $30.765 \mathrm{~ms})\left(\mathrm{M}_{\text {difference }}=41.211,95 \%\right.$ CI $\left.[26.384,56.037]\right)$ and a long $(\mathrm{M}=288.317 \mathrm{~ms}, \mathrm{SD}=$ $27.306 \mathrm{~ms})\left(\mathrm{M}_{\text {difference }}=46.196,95 \%\right.$ CI $\left.[25.998,66.394]\right)$ distance. There was no significant difference when comparing the intermediate to the long distance of movement $(F(1,9)=$ $\left.2.669, p=.137, \eta^{2} \mathrm{p}=.229\right)\left(\mathrm{M}_{\text {difference }}=4.985,95 \%\right.$ CI $\left.[-1.918,11.888]\right)($ see Figure 8$)$.

\section{Discussion}

Regarding the bisection bias for the most lateral lines, this second experiment yielded results comparable to the ones observed in the first experiment. Additional results will be discussed in the general discussion section.

When comparing only the lines whose center was situated at a distance of $0 \mathrm{~cm}$ with regard to the median vertical of the mirror, we observed significant systematic right-ward biases in the two conditions where the lines the furthest from the starting point corresponded to the lines close to the body midline (right/distant and right/central conditions), but not for the lines close to the body midline and close to the starting point (left/distant condition). This 
bisection bias to the inside of the workspace observed for the most lateral lines in Experiment 1 seemed thus not due to the distance from the line to the body midline, but to the fact that the distance to cover from the starting point to the line was the longest.

As for the movement initiation time, results from the first experiment were replicated, showing that participants took more time to initiate movements when they had to cover a short distance as compared to intermediate and long distances, independently from the distance of the line to the body midline.

\section{General discussion}

We adapted the classic line bisection task for the use in a robot-assisted virtual reality system, with the aim to measure discrete biases in spatial perception that can usually not be assessed with the traditional neuropsychological tasks that have been designed for the assessment of hemispatial neglect.

This study investigated the ability to search for and reach to visual stimuli in the space surrounding the upper limbs. The task was tested with healthy participants and results showed that some of the manipulated experimental factors were able to influence line bisection performance of the participants. We manipulated which hand was used to reach and cross the lines and which hand remained static (static hand), where the static hand was placed (static hand position), whether the participants could see their hand within the workspace and the surrounding devices (vision of the hands/workspace), as well as where the lines were presented within the participant's visual field and relative to their body (line location/distance). The two experiments showed that participants made generally more bisection errors when they could see their hands and the workspace as compared to the conditions where they only saw the stimuli and the cursor. This finding falls into line with the observation that reducing surrounding visual information can improve visuo-spatial performance in spatial neglect (Chokron, Colliot, \& Bartolomeo, 2004; Gassama, Deplancke, 
Saj, Honore, \& Rousseaux, 2011; Hjaltason \& Tegner, 1992). This could be due to the fact that attention is less captured by visual distractors.

Another finding of Experiment 1 was that healthy participants present a bisection bias to the inside of the workspace (a right-ward bias for left-sided lines and a left-ward bias for right-sided lines) when they bisect the lines situated the most laterally from the starting point, as compared to the two other line locations. This result can only partially be explained by the concept of pseudoneglect, a slight, but systematic left-ward bisection bias observed in neurologically intact individuals (Bowers \& Heilman, 1980), because of the right-ward bisection bias for lines presented in the left hemispace. This well-described phenomenon of pseudoneglect can however be significantly modulated to varying degrees by several stimulus, subject or performance factors (Benwell, Harvey, Gardner, \& Thut, 2013; Heber et al., 2010; Jewell \& McCourt, 2000; Schmitz \& Peigneux, 2011). One possible explanation for the two different directional biases for the two hemi-spaces could be for example that there seems to be a relative bias in the direction of the hand used to perform the bisection (Jewell \& McCourt, 2000), related to the asymmetry of cerebral activation induced by unilateral limb use. One of the largest modulating effects on bisection bias pointed out in Jewell and McCourt (2000)'s meta-analysis was the initial visual or motor scanning direction of participants, with a left-to-right scanning pattern leading to a left-sided bisection bias and a right-to-left scanning pattern to a right-sided bisection bias. This effect of scanning direction could provide a possible explanation for the bisection bias to the inside of the workspace we observed in our experiments, provided that participants initiated visual scanning from the starting point. We didn't control participants' scanning directions, but the experimental set-up of the robotic device requires left-to-right movements for right-sided stimuli and right-to-left movements for left-sided stimuli (due to mechanical constraints and starting point position) it seems thus probable that participants initiated visual scanning following hand movements. 
Eye-tracking techniques can be used to assess scanning direction in visuo-spatial attention tasks (see for example Thomas, Loetscher, and Nicholls (2014)). In our case they could be of interest to determine why there is a left-ward bias for the short distance of movement in the two new conditions of our second study. Other modulating factors, as for example the spatial location of lines (i.e. left/right hemifield or center) or the presence of visual cues, have been discussed in the literature (see Jewell \& McCourt, 2000), but the large variability among studies makes interpretations difficult.

Another question raised in line with the results of Experiment 1 was whether this bisection bias for lines at a lateral location was due to the fact that they were the most distant from the body midline or to the fact that the distance to cover (from the starting point to the line) was the longest. The second experiment was designed to address this question, by adding conditions where the lines the closest to the body midline were also the lines the furthest away from the starting point. Results showed that the bisection bias to the inside of the workspace observed for the most lateral lines seemed not due to the distance from the line to the body midline, but to the fact that the distance to cover from the starting point to the line was the longest.

Although factors as hand use and scanning directions could potentially explain why participants biased their bisections to the inside of the workspace, they cannot explain that these bisection biases were only shown for the most lateral lines in the first experiment. It has to be noted that, based on the results of the second experiment, this seems to be rather an effect of distance than of a specific spatial location, with bisection biases that seem to increase with increasing distance of movement, as shown by the fact that bisection biases are significantly smaller for the short as compared to the, respectively, intermediate and long distance of movement, whereas there's no significant difference between the intermediate and the long distance of movement. 
Experiment 1 also showed that the participants took significantly more time to initiate movements to the lines at a more medial location than to the lines at intermediate and lateral locations. Experiment 2 replicated this result and showed that it was due to the fact that participants had to cover a short distance from the starting point to the line, and not to the fact that lines were close to the body midline. This gain in movement initiation time when movements are made towards lines at more intermediate and lateral locations could be explained by an overlap in movement planning and execution (Haith, Pakpoor, \& Krakauer, 2016), which would not be the case when the lines are presented in the medial location, i.e. in front of the starting point. This seems to be related to differences in the curvatures of the movement to bisect the lines, with participants making more straight movements when the line is in front of the starting point and more curved movements when the lines are presented more sideways (Orban de Xivry, Legrain, \& Lefèvre, 2017). More precisely, Orban de Xivry et al. (2017) showed that more curved movements start with a transport phase during which accuracy demands are not taken into account, which in turn allows to refine the movement plan with respect to accuracy demands after movement onset, thus resulting in a gain of movement initiation time.

As for the factors static hand and static hand position, neither Experiment 1, nor Experiment 2 showed significant main effects or interactions. However, especially for the static hand position, a modulating effect could have been expected, even in healthy participants. Studies showed that flanking objects in general can influence line bisection in healthy participants (Chieffi, 1999). More specifically, that the position of the arm for example can have an impact on line bisection performance was recently shown (Seraglia, Priftis, Cutini, \& Gamberini, 2012). In Seraglia et al. (2012)'s study however, it was the position of the active arm which influenced performance, whereas we are studying the effects of the position of the passive arm. Other studies have shown facilitating effects of hand 
proximity on visual perception in patients with right primary visual cortex damage (Schendel \& Robertson, 2004), visual extinction (di Pellegrino \& Frassinetti, 2000) and on spatial attentional prioritization in healthy participants (Reed, Grubb, \& Steele, 2006). In Sposito, Bolognini, Vallar, Posteraro, and Maravita (2010)'s study, right brain-damaged patients with hemispatial neglect and neurologically unimpaired participants had to perform either bisection on their forearm or an extracorporal object. Results showed that in the two groups, bisections were done more accurately when they were performed on their forearm as when they were performed on external objects. It has to be noted that we didn't include a condition in which the static arm was completely absent from the workspace. Even if in half of the conditions the arm was placed outside of the workspace we cannot exclude that its visually or proprioceptively perceived presence influenced line bisections.

Spatial perception and body representation can be affected in various ways. It can affect different sensory modalities and/or the motor domain, but also different frames of spatial reference. Most of the traditional screening methods however are conceived to test visual spatial capacities in the space external to the body. These tasks are often reported being not sensitive and informative enough to assess neglect in right hemisphere brain-damaged patients (Azouvi et al., 2002; Bonato, 2012; Bonato \& Deouell, 2013) and seem also inadequate to reveal probably discrete spatial asymmetries consecutive to sensori-motor impairments. It has been hypothesized that subjective space perception is in fact directly dependent upon previous and ongoing sensori-motor interactions with the environment and that asymmetric sensori-motor experience can bias spatial perception (Dupierrix et al., 2008; Dupierrix et al., 2009). This has been shown by experimentally inducing sensori-motor-spatial relationships with lateralized pointing tasks (Dupierrix et al., 2008; Dupierrix et al., 2009) or sensori-motor adaptation (i.e. prism adaptation) (Berberovic \& Mattingley, 2003; Michel et al., 2003) with healthy individuals, but also in some studies including patients with sensori- 
motor deficits. In CRPS patients for example, distortions of the egocentric reference frame (Sumitani, Shibata, et al., 2007; Uematsu et al., 2009) and a lateralized spatial bias in tactile and visual processing (Bultitude et al., 2017; Filbrich et al., 2017; Moseley et al., 2009) have been demonstrated, as well as symptoms suggesting a distorted representation of the affected limb. Furthermore, prismatic adaptation, a therapy that is often used effectively to treat visuospatial deficits in hemispatial neglect patients, has also been shown beneficial in reducing pain and other related symptoms in CRPS (Bultitude \& Rafal, 2010; Christophe et al., 2016; Jacquin-Courtois et al., 2012; Sumitani, Rossetti, et al., 2007). Alterations in space perception can also be observed in hemiplegic patients without classical symptoms of hemispatial neglect (Bartolo, Carlier, Hassaini, Martin, \& Coello, 2014) or after unilateral hand amputation (Makin et al., 2010). Nevertheless, perceptual difficulties are rarely investigated in patients suffering from predominantly sensori-motor deficits, probably because there are rarely adequate assessment methods. Our task was thus conceived with the aim to create a more sensitive measure of discrete impairments in space perception and body representation. Our robotic adaptation of the line bisection task was able to highlight subtle perceptual asymmetries in healthy participants that would probably not have been detected with the standard version of the task. Its use in patients with upper-limb sensori-motor deficits seems thus promising. The task has the advantage that the testing environment is very easily and well controlled. It allows controlling and manipulating the utilization of different frames of reference by varying the exact position of the presented stimuli. It allows not only the assessment of visuo-spatial capacities in external space, but takes also into account the space of the body itself, by varying the position of the limbs in the workspace and/or according to the stimuli. The visual environment, i.e. the presence of distracting stimuli, can also be manipulated. Another interesting aspect of the task is that it can easily dissociate between motor and perceptual impairment in exploring space, for instance by opposing the space 
where the visual target is located and the direction of the movement to reach that space. Exact measurements of movement initiation time can be of interest to explore motor initiation capacities (i.e. motor neglect). Because we use a computerized virtual reality system, assessment from one session to the next and between patients is standardized and repeatable and due to its flexible stimulus presentation also less prone to ceiling and compensation effects.

This study allowed us to evaluate the mechanical and cognitive constraints of reaching-to-point movement in our robot-assisted line bisection task, with the aim to control these parameters when evaluating cognitive deficits in patients with sensori-motor impairments. 


\section{References}

Azouvi, P., Samuel, C., Louis-Dreyfus, A., Bernati, T., Bartolomeo, P., Beis, J.-M., . . Rousseaux, M. (2002). Sensitivity of clinical and behavioural tests of spatial neglect after right hemisphere stroke. Journal of Neurology, Neurosurgery, and Psychiatry, 73, 160-166.

Baheux, K., Yoshizawa, M., Seki, K., \& Handa, Y. (2006). Virtual Reality Pencil and Paper Tests for Neglect: A Protocol. Cyberpsychology \& Behavior, 9(2), 192-195.

Bartolo, A., Carlier, M., Hassaini, S., Martin, Y., \& Coello, Y. (2014). The perception of peripersonal space in right and left brain damage hemiplegic patients. Front Hum Neurosci, 8, 3. doi: 10.3389/fnhum.2014.00003

Benwell, C. S., Harvey, M., Gardner, S., \& Thut, G. (2013). Stimulus- and state-dependence of systematic bias in spatial attention: additive effects of stimulus-size and time-on-task. Cortex, 49(3), 827-836. doi: 10.1016/j.cortex.2011.12.007

Berberovic, N., \& Mattingley, J. B. (2003). Effects of prismatic adaptation on judgments of spatial extent in peripersonal and extrapersonal space. Neuropsychologia, 41, 493-503.

Bisiach, E., Geminiani, G., Berti, A., \& Rusconi, M. L. (1990). Perceptual and premotor factors of unilateral neglect. Neurology, $40(8), 1278-1278$. doi: 10.1212/wnl.40.8.1278

Bonato, M. (2012). Neglect and extinction depend greatly on task demands: a review. Front. Hum. Neurosci., 6, 195. doi: 10.3389/fnhum.2012.00195

Bonato, M., \& Deouell, L. Y. (2013). Hemispatial neglect: computer-based testing allows more sensitive quantification of attentional disorders and recovery and might lead to better evaluation of rehabilitation. Front. Hum. Neurosci., 7, 162. doi: 10.3389/fnhum.2013.00162

Bowers, D., \& Heilman, K. M. (1980). Pseudoneglect: effects of hemispace on a tactile line bisection task. Neuropsychologia, 18, 491-498.

Brozzoli, C., Demattè, M. L., Pavani, F., Frassinetti, F., \& Farne, A. (2006). Neglect and extinction : Within and between sensory modalities. Restor Neurol Neurosci, 24, 217-232.

Bultitude, J. H., \& Rafal, R. D. (2010). Derangement of body representation in complex regional pain syndrome: report of a case treated with mirror and prisms. Exp Brain Res, 204(3), 409-418. doi: 10.1007/s00221-009-2107-8

Bultitude, J. H., Walker, I., \& Spence, C. (2017). Biased covert visual attention to body and space in complex regional pain syndrome. Brain, Forthcoming.

Caramazza, A., \& Hillis, A. E. (1990). Spatial representation of words in the brain implied by studies of a unilateral neglect patient. Nature, 346(6281), 267-269.

Cardinali, L., Brozzoli, C., \& Farne, A. (2009). Peripersonal space and body schema: two labels for the same concept? Brain Topogr, 21(3-4), 252-260. doi: 10.1007/s10548-009-0092-7

Chieffi, S. (1999). Influence of perceptual factors on line bisection. Cortex, 35, 523-536. doi: 10.1016/S0010-9452(08)70816-5

Chokron, S., Colliot, P., \& Bartolomeo, P. (2004). The role of vision in spatial representation. Cortex, 40(2), 281-290. doi: 10.1016/S0010-9452(08)70123-0

Christophe, L., Chabanat, E., Delporte, L., Revol, P., Volckmann, P., Jacquin-Courtois, S., \& Rossetti, Y. (2016). Prisms to shift pain away: pathophysiological and therapeutic exploration of CRPS with prism adaptation. Neural Plast, 1694256. doi: 10.1155/2016/1694256

de Bruin, N., Bryant, D. C., \& Gonzalez, C. L. (2014). "Left neglected," but only in far space: spatial biases in healthy participants revealed in a visually guided grasping task. Front Neurol, 5, 4. doi: 10.3389/fneur.2014.00004

di Pellegrino, G., \& Frassinetti, F. (2000). Direct evidence from parietal extinction of enhancement of visual attention near a visible hand. Current Biology, 10, 1475-1477.

di Pellegrino, G., Làdavas, E., \& Farné, A. (1997). Seeing where your hands are. Nature, 388, 730. 
Dupierrix, E., Alleysson, D., Ohlmann, T., \& Chokron, S. (2008). Spatial bias induced by a nonconflictual task reveals the nature of space perception. Brain Res, 1214, 127-135. doi: 10.1016/j.brainres.2008.01.021

Dupierrix, E., Gresty, M., Ohlmann, T., \& Chokron, S. (2009). Long lasting egocentric disorientation induced by normal sensori-motor spatial interaction. PLOS ONE, 4(2). doi: 10.1371/journal.pone.0004465.t001

Filbrich, L., Alamia, A., Verfaille, C., Berquin, A., Barbier, O., Libouton, X., . . Legrain, V. (2017). Biased visuospatial perception in complex regional pain syndrome. Sci Rep, 7(1), 9712. doi: 10.1038/s41598-017-10077-8

Fordell, H., Bodin, K., Bucht, G., \& Malm, J. (2011). A virtual reality test battery for assessment and screening of spatial neglect. Acta Neurol Scand, 123(3), 167-174. doi: 10.1111/j.16000404.2010.01390.x

Forderreuther, S., Sailer, U., \& Straube, A. (2004). Impaired self-perception of the hand in complex regional pain syndrome (CRPS). Pain, 110(3), 756-761. doi: 10.1016/j.pain.2004.05.019

Galer, B. S., Butler, S., \& Jensen, M. P. (1995). Case Reports and Hypothesis: A Neglect-Like Syndrome May Be Responsible for the Motor Disturbance in Reflex Sympathetic Dystrophy (Complex Regional Pain Syndrome-1). Journal of Pain and Symptom Management, 10(5), 385-391.

Galer, B. S., \& Jensen, M. P. (1999). Neglect-Like Symptoms in Complex Regional Pain Syndrome: Results of a Self-Administered Survey. Journal of Pain and Symptom Management, 18(3), 213-217.

Gamberini, L., Seraglia, B., \& Priftis, K. (2008). Processing of peripersonal and extrapersonal space using tools: evidence from visual line bisection in real and virtual environments. Neuropsychologia, 46(5), 1298-1304. doi: 10.1016/j.neuropsychologia.2007.12.016

Gassama, S., Deplancke, A., Saj, A., Honore, J., \& Rousseaux, M. (2011). Do supine position and deprivation of visual environment influence spatial neglect? J Neurol, 258(7), 1288-1294. doi: 10.1007/s00415-011-5926-z

Guariglia, C., \& Antonucci, G. (1992). Personal and extrapersonal space: A case of neglect dissociation. Neuropsychologia, 30(11), 1001-1009.

Hach, S., \& Schutz-Bosbach, S. (2014). In (or outside of) your neck of the woods: laterality in spatial body representation. Front Psychol, 5, 123. doi: 10.3389/fpsyg.2014.00123

Haith, A. M., Pakpoor, J., \& Krakauer, J. W. (2016). Independence of Movement Preparation and Movement Initiation. The Journal of Neuroscience, 36(10), 3007-3015. doi: 10.1523/jneurosci.3245-15.2016

Halligan, P. W., Fink, G. R., Marshall, J. C., \& Vallar, G. (2003). Spatial cognition: evidence from visual neglect. Trends in Cognitive Sciences, 7(3), 125-133. doi: 10.1016/s1364-6613(03)00032-9

Halligan, P. W., \& Marshall, J. C. (1991). Left neglect for near but not far space in man. Nature, 350, 498-500.

Harden, R. N., Bruehl, S., Perez, R. S., Birklein, F., Marinus, J., Maihofner, C., . . Vatine, J. J. (2010). Validation of proposed diagnostic criteria (the "Budapest Criteria") for Complex Regional Pain Syndrome. Pain, 150(2), 268-274. doi: 10.1016/j.pain.2010.04.030

Harvey, M. (2004). Perceptual and Premotor Neglect: Is there an Ideal Task to Categorise Patients? Cortex, 40(2), 323-328. doi: https://doi.org/10.1016/S0010-9452(08)70127-8

Heber, I. A., Siebertz, S., Wolter, M., Kuhlen, T., \& Fimm, B. (2010). Horizontal and vertical pseudoneglect in peri- and extrapersonal space. Brain Cogn, 73(3), 160-166. doi: 10.1016/j.bandc.2010.04.006

Hjaltason, H., \& Tegner, R. (1992). Darkness Improves Line Bisection in Unilateral Spatial Neglect. Cortex, 28(3), 353-358.

Husain, M., Mattingley, J. B., Rorden, C., Kennard, C., \& Driver, J. (2000). Distinguishing sensory and motor biases in parietal and frontal neglect. Brain, 123, 1643-1659.

Jacobs, S., Brozzoli, C., \& Farne, A. (2012). Neglect: a multisensory deficit? Neuropsychologia, 50(6), 1029-1044. doi: 10.1016/j.neuropsychologia.2012.03.018 
Jacquin-Courtois, S., Rossetti, Y., Legrain, V., Sumitani, M., \& Miyauchi, S. (2012). Adaptation visuomotrice et représentations corporelles: de la négligence au syndrome douloureux régional complexe. La Lettre de médecine physique et de réadaptation, 28(2), 93-98. doi: 10.1007/s11659-012-0315-2

Jewell, G., \& McCourt, M. E. (2000). Pseudoneglect: a review and meta-analysis of performance factors in line bisection tasks. Neuropsychologia, 38, 93-110.

Kerkhoff, G. (2001). Spatial hemineglect in humans. Progress in Neurobiology, 63, 1-27.

Kolb, L., Lang, C., Seifert, F., \& Maihofner, C. (2012). Cognitive correlates of "neglect-like syndrome" in patients with complex regional pain syndrome. Pain, 153(5), 1063-1073. doi: 10.1016/j.pain.2012.02.014

Landis, T. (2000). Disruption of space perception due to cortical lesions. Spatial Vision, 13(2,3), 179191.

Legrain, V., Bultitude, J. H., De Paepe, A. L., \& Rossetti, Y. (2012). Pain, body, and space: what do patients with complex regional pain syndrome really neglect? Pain, 153(5), 948-951. doi: 10.1016/j.pain.2011.12.010

Lewis, J. S., Kersten, P., McCabe, C. S., McPherson, K. M., \& Blake, D. R. (2007). Body perception disturbance: a contribution to pain in complex regional pain syndrome (CRPS). Pain, 133(1-3), 111-119. doi: 10.1016/j.pain.2007.03.013

Makin, T. R., Wilf, M., Schwartz, I., \& Zohary, E. (2010). Amputees "neglect" the space near their missing hand. Psychol Sci, 21(1), 55-57. doi: 10.1177/0956797609354739

Marinus, J., Moseley, G. L., Birklein, F., Baron, R., Maihöfner, C., Kingery, W. S., \& van Hilten, J. J. (2011). Clinical features and pathophysiology of complex regional pain syndrome. Lancet Neurol, 10(7), 637-648. doi: 10.1016/s1474-4422(11)70106-5

McCabe, C. S., Haigh, R. C., Halligan, P. W., \& Blake, D. R. (2003). Referred sensations in patients with complex regional pain syndrome type 1. Rheumatology (Oxford), 42(9), 1067-1073. doi: 10.1093/rheumatology/keg298

Michel, C., Pisella, L., Halligan, P. W., Luauté, J., Rode, G., Boisson, D., \& Rossetti, Y. (2003). Simulating unilateral neglect in normals using prism adaptation: implications for theory. . Neuropsychologia, 41, 25-39.

Moseley, G. L. (2004). Why do people with complex regional pain syndrome take longer to recognize their affected hand? . Neurology, 62, 2182-2186.

Moseley, G. L. (2005). Distorted body image in complex regional pain syndrome. Neurology, 65, 773.

Moseley, G. L., Gallace, A., \& Spence, C. (2009). Space-based, but not arm-based, shift in tactile processing in complex regional pain syndrome and its relationship to cooling of the affected limb. Brain, 132(Pt 11), 3142-3151. doi: 10.1093/brain/awp224

Nicholls, M. E., Thomas, N. A., Loetscher, T., \& Grimshaw, G. M. (2013). The Flinders Handedness survey (FLANDERS): a brief measure of skilled hand preference. Cortex, 49(10), 2914-2926. doi: 10.1016/j.cortex.2013.02.002

Orban de Xivry, J.-J. (2013). Trial-to-Trial Reoptimization of Motor Behavior Due to Changes in Task Demands Is Limited. PLOS ONE, 8(6). doi: 10.1371/

Orban de Xivry, J.-J., Legrain, V., \& Lefèvre, P. (2017). Overlap of movement planning and movement execution reduces reaction time. Journal of Neurophysiology, 117(1), 117-122. doi: $10.1152 / \mathrm{jn} .00728 .2016$

Previc, F. H. (1998). The Neuropsychology of 3-D Space. Psychological Bulletin, 124(2), 123-164.

Punt, T. D., Cooper, L., Hey, M., \& Johnson, M. I. (2013). Neglect-like symptoms in complex regional pain syndrome: learned nonuse by another name? Pain, 154(2), 200-203. doi: 10.1016/j.pain.2012.11.006

Reed, C. L., Grubb, J. D., \& Steele, C. (2006). Hands up: attentional prioritization of space near the hand. Journal of Experimental Psychology: Human Perception and Performance, 32(1), 166177. doi: 10.1037/0096-1523.32.1.166 
Reid, E., Wallwork, S. B., Harvie, D., Chalmers, K. J., Gallace, A., Spence, C., \& Moseley, G. L. (2016). A New Kind of Spatial Inattention Associated With Chronic Limb Pain? Ann Neurol, 79(4), 701704. doi: 10.1002/ana.24616

Reinersmann, A., Landwehrt, J., Krumova, E. K., Ocklenburg, S., Gunturkun, O., \& Maier, C. (2012). Impaired spatial body representation in complex regional pain syndrome type 1 (CRPS I). Pain, 153(11), 2174-2181. doi: 10.1016/j.pain.2012.05.025

Rose, F. D., Brooks, B. M., \& Rizzo, A. A. (2005). Virtual reality in brain damage rehabilitation : review. Cyberpsychol Behav, 8(3), 241-262.

Schendel, K., \& Robertson, L. C. (2004). Reaching Out to See: Arm Position Can Attenuate Human Visual Loss. Journal of Cognitive Neuroscience, 16(6), 935-943.

Schmitz, R., \& Peigneux, P. (2011). Age-related changes in visual pseudoneglect. Brain Cogn, 76(3), 382-389. doi: 10.1016/j.bandc.2011.04.002

Schwoebel, J., \& Coslett, H. B. (2005). Evidence for Multiple, Distinct Representations of the Human Body. Journal of Cognitive Neuroscience, 17(4), 543-553.

Schwoebel, J., Friedman, R., Duda, N., \& Coslett, H. B. (2001). Pain and the body schema. Evidence for peripheral effects on mental representations of movement. Brain, 124, 2098-2104.

Seraglia, B., Priftis, K., Cutini, S., \& Gamberini, L. (2012). How tool use and arm position affect peripersonal space representation. Cogn Process, 13 Suppl 1, S325-328. doi: 10.1007/s10339012-0458-8

Smania, N., \& Aglioti, S. (1995). Sensory and spatial components of somaesthetic deficits following right brain damage. Neurology, 45(9), 1725-1730.

Sposito, A. V., Bolognini, N., Vallar, G., Posteraro, L., \& Maravita, A. (2010). The spatial encoding of body parts in patients with neglect and neurologically unimpaired participants. Neuropsychologia, 48(1), 334-340. doi: 10.1016/j.neuropsychologia.2009.09.026

Sumitani, M., Rossetti, Y., Shibata, M., Matsuda, Y., Sakaue, G., Inoue, T., . . Miyauchi, S. (2007). Prism adaptation to optical deviation alleviates pathologic pain Neurol, 68, 128-133.

Sumitani, M., Shibata, M., Iwakura, T., Matsuda, Y., Sakaue, G., Inoue, T., . . Miyauchi, S. (2007). Pathologic pain distorts visuospatial perception. Neurol, 68(2), 152-154. doi: 10.1212/01.wnl.0000250335.56958.fO

Thomas, N. A., Loetscher, T., \& Nicholls, M. E. (2014). Asymmetries in attention as revealed by fixations and saccades. Exp Brain Res, 232(10), 3253-3267. doi: 10.1007/s00221-014-4015-9

Tsirlin, I., Dupierrix, E., Chokron, S., Coquillart, S., \& Ohlmann, T. (2009). Uses of virtual reality for diagnosis, rehabilitation and study of unilateral spatial neglect: review and analysis. Cyberpsychol Behav, 12(2), 175-181. doi: 10.1089/cpb.2008.0208

Uematsu, H., Sumitani, M., Yozu, A., Otake, Y., Shibata, M., Mashimo, T., \& Miyauchi, S. (2009). Complex Regional Pain Syndrome (CRPS) Impairs Visuospatial Perception, whereas PostHerpetic Neuralgia does not: Possible Implications for Supraspinal Mechanism of CRPS. Ann Acad Med Singapore, 38, 931-936.

Vaes, N., Lafosse, C., Nys, G., Schevernels, H., Dereymaeker, L., Oostra, K., . . Vingerhoets, G. (2014). Capturing peripersonal spatial neglect: An electronic method to quantify visuospatial processes. Behav Res Methods. doi: 10.3758/s13428-014-0448-0

Vallar, G. (1998). Spatial hemineglect in humans. Trends in Cognitive Sciences, 2(3), 87-97.

Vallar, G., \& Maravita, A. (2009). Personal and extrapersonal spatial perception. In G. G. Berntson \& J. T. Cacioppo (Eds.), Handbook of Neuroscience for the Behavioral Sciences (Vol. 1, pp. 322336). New York: John Wiley \& Sons. 


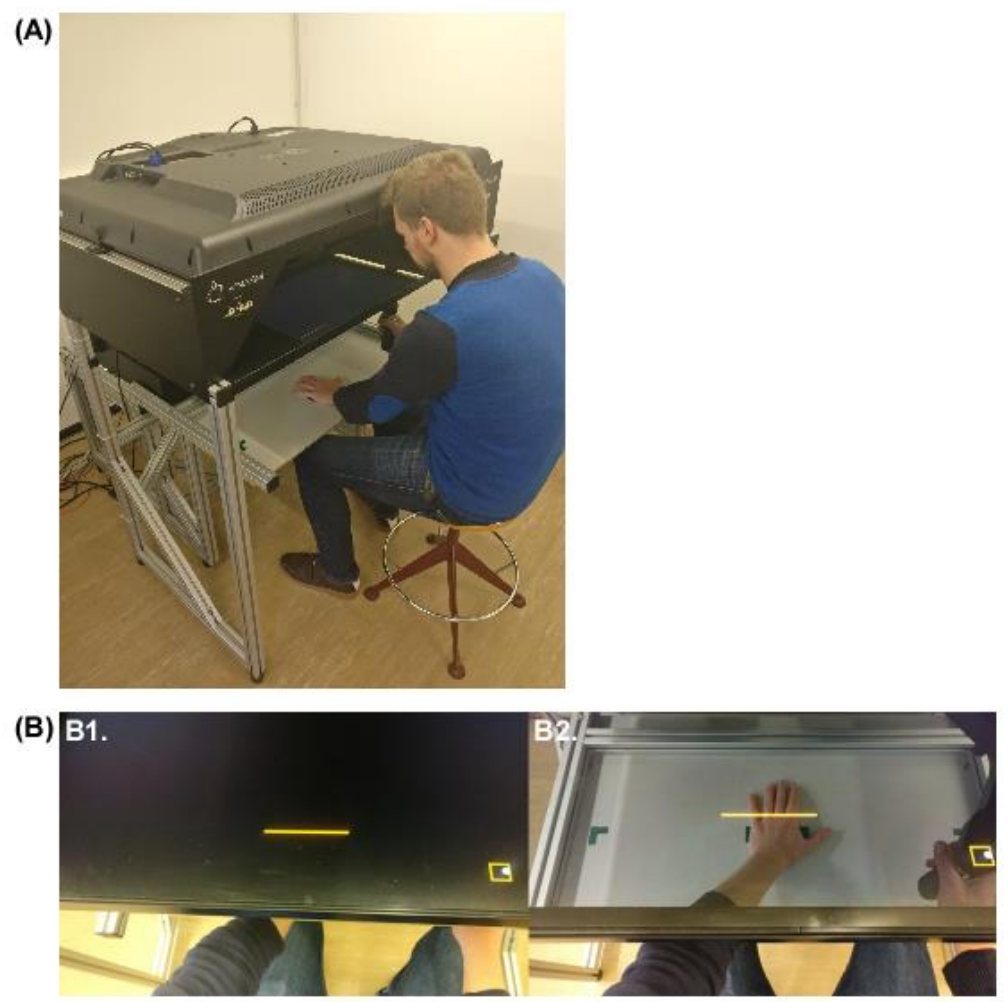

Figure 1. Illustration of the robotic system $\operatorname{Kinarm}^{\mathrm{TM}}$. (A) The robotic section with one of the graspable handles and the horizontal semi-reflective mirrored screen for the virtual reality environment, as well as the table on which one hand of the participants was placed. (B) A store under the mirror can either be closed (B1) or opened (B2), to preclude or provide vision of the hands and of the workspace, respectively. 
ROBOT-ASSISTED LINE BISECTION TEST IN VIRTUAL REALITY

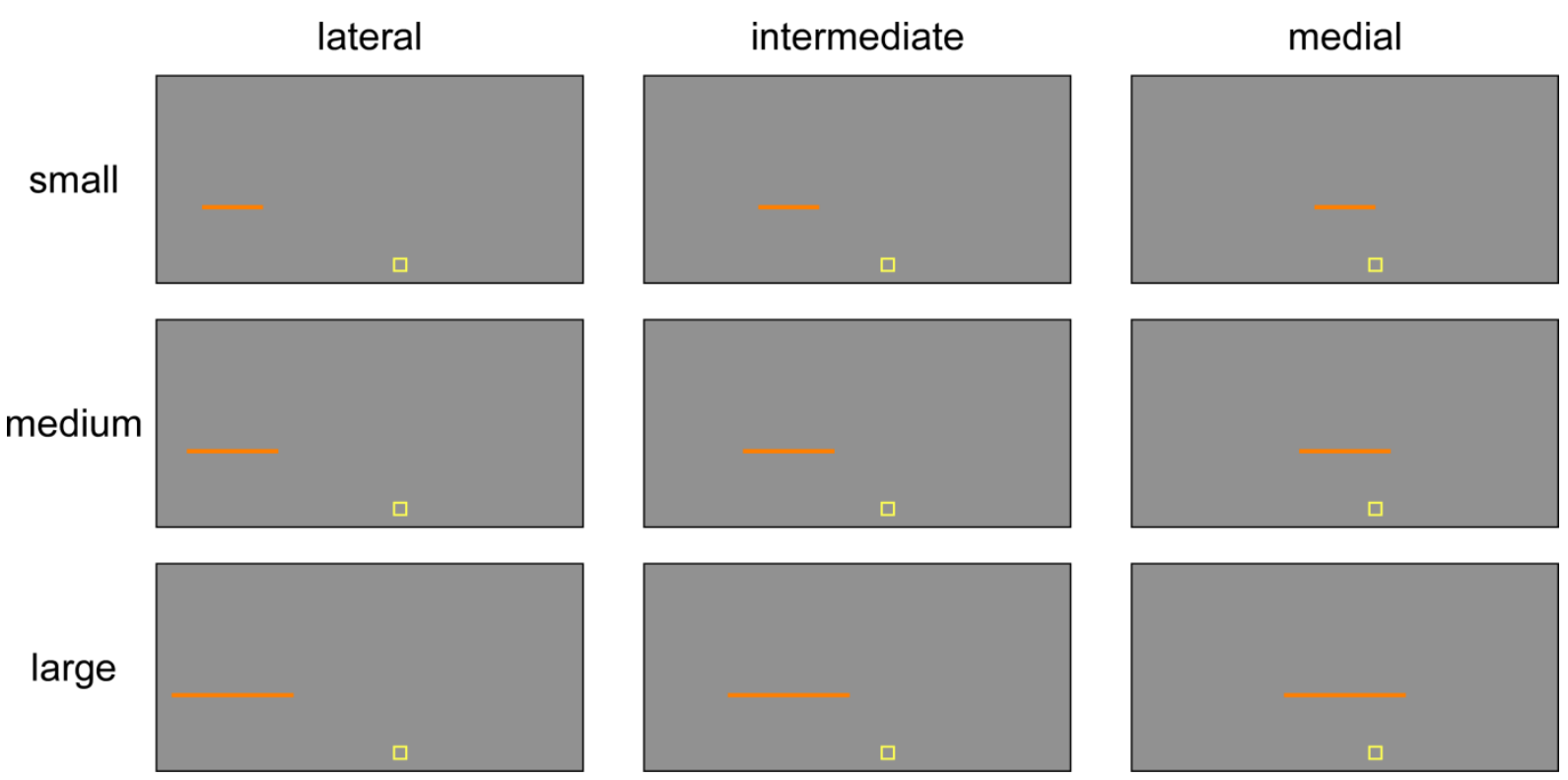

Figure 2.Schematic of various visual stimuli dimensions and locations with regard to the vertical median of the mirror in Experiment 1, illustrated here for the left hemi-side of the workspace. 
1. hands visible

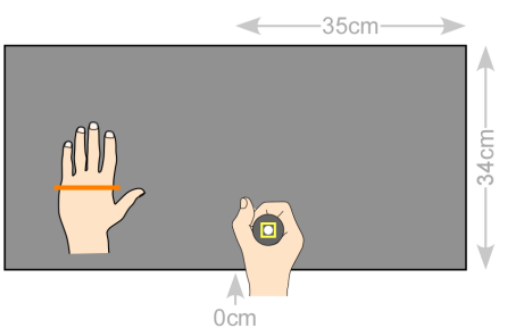

B. static hand outside

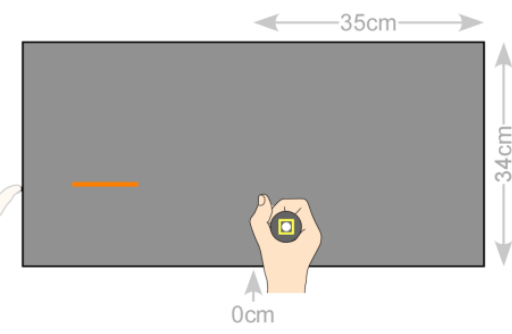

2. hands invisible
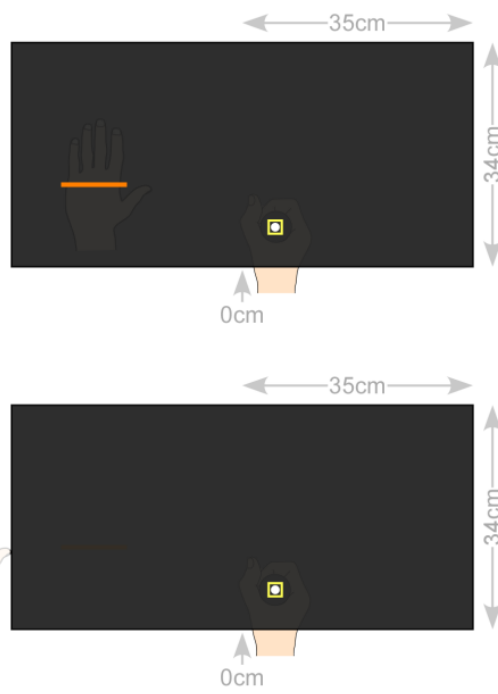

Figure 3.Schematic of the four experimental conditions in Experiment 1. The conditions were defined by combining the factors static hand position (static hand inside the workspace $[\mathrm{A}]$ or outside the workspace [B]) and vision (hands visible [1] or invisible [2]). They were repeated two times, by switching the static and active hands. The hand next to the yellow starting square represents the active hand. 

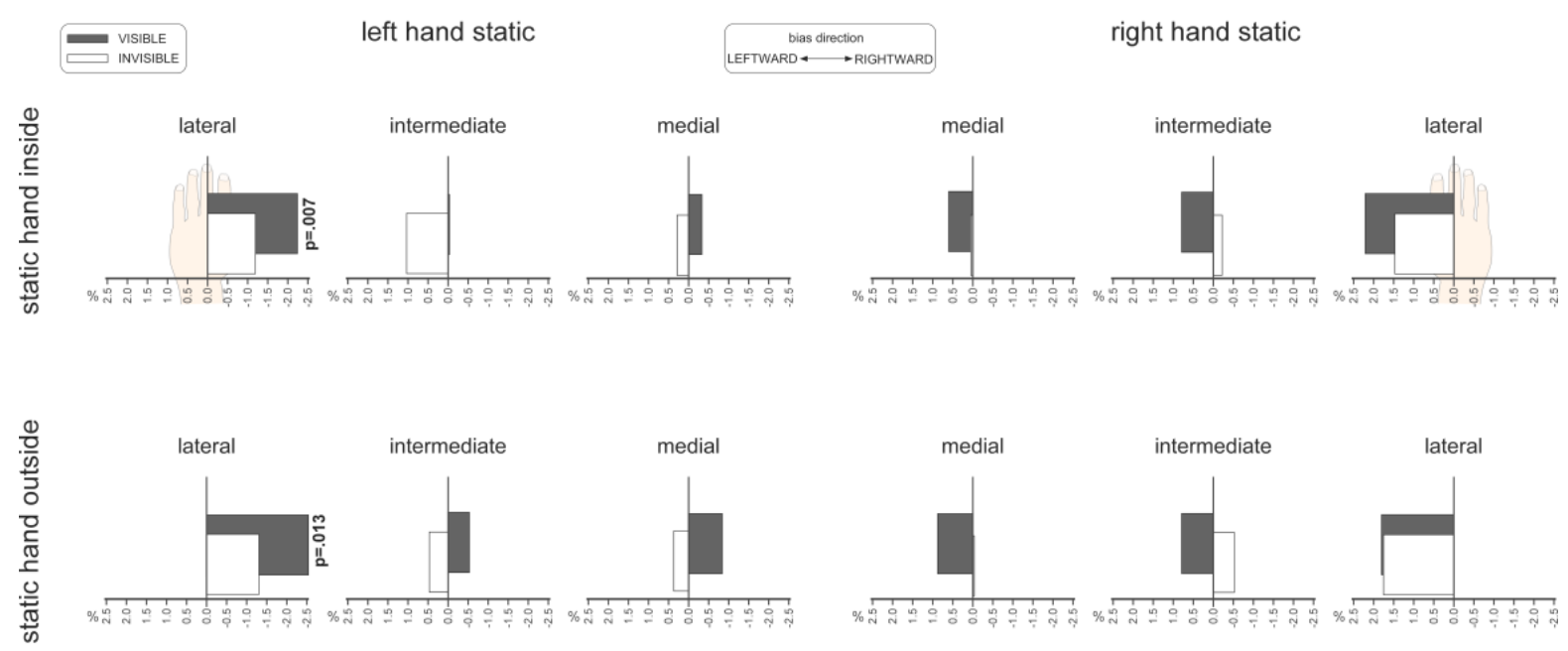

Figure 4. Mean bisection biases (\% of deviation) from the ten participants for the four experimental conditions and for each line location with regard to the median vertical of the mirror in Experiment 1, as a function of static hand. Data from the three line lengths were merged. 


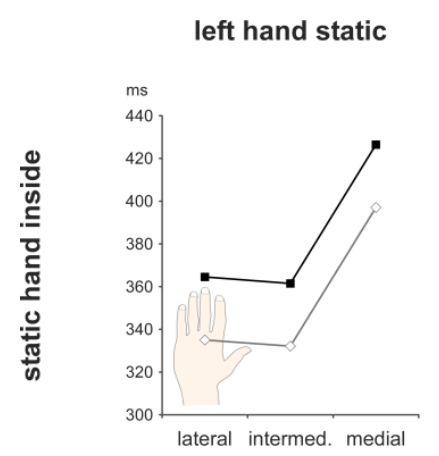

right hand static
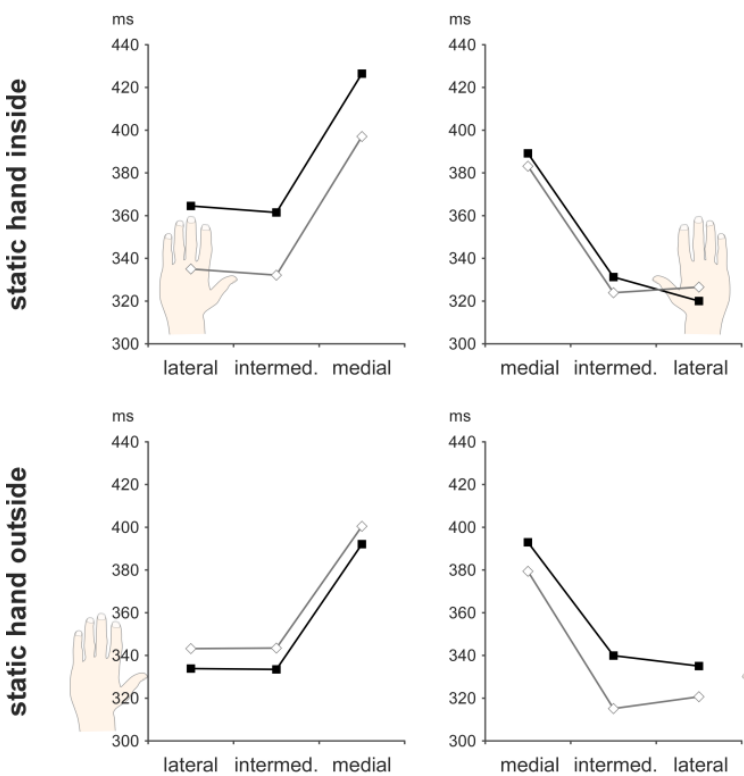

$\underset{\sim-}{\longrightarrow}$ invisible

Figure 5. Mean movement initiation times (ms) from the ten participants for the four experimental conditions and for each line location with regard to the median vertical of the mirror in Experiment 1, as a function of static hand. Data from the three line lengths were merged. 
1. hands visible

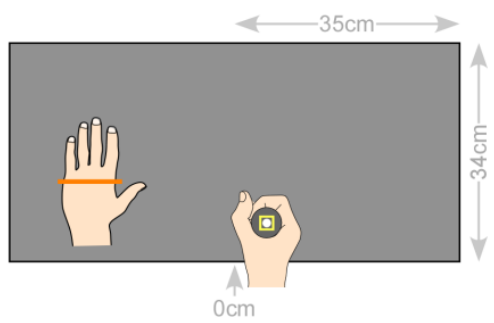

A. lines in left space left hand distant

\section{B. lines in right space left hand distant}

\section{C. lines in right space left hand central}
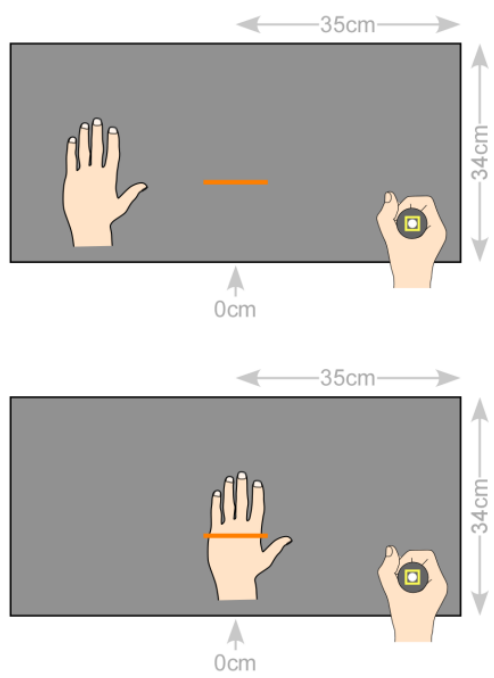

2. hands invisible
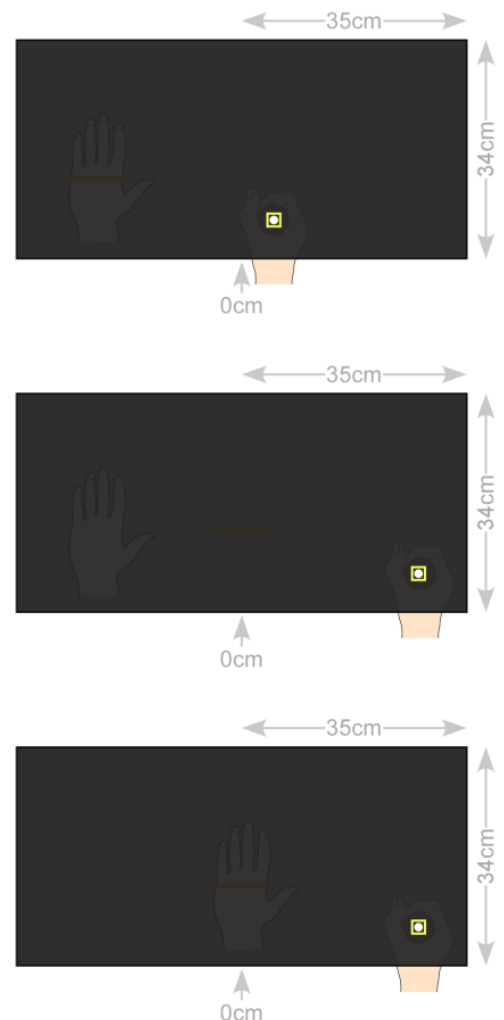

Figure 6. Schematic of the six experimental conditions in Experiment 2. The conditions were defined by combining the factors position of the lines and of the static hand (lines projected in the left work-space and the static hand placed in a distant position [A], lines projected in the right work-space and the static hand placed in a distant position [B] or lines projected in the right workspace and the static hand placed in a central position) and vision (hands visible [1] or invisible [2]). The hand next to the yellow starting square represents the active hand. 

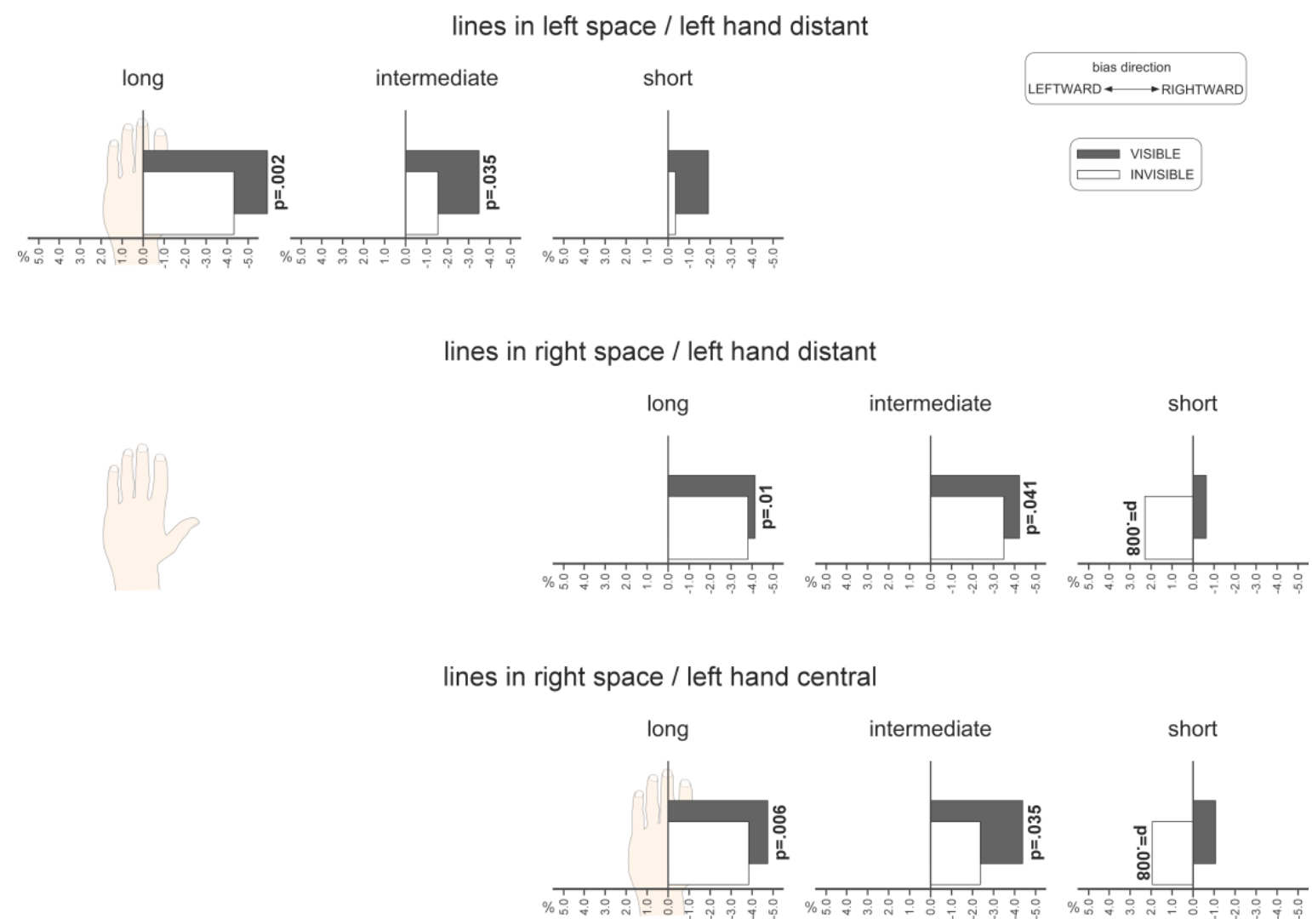

Figure 7. Mean bisection biases (\% of deviation) from the ten participants for the six experimental conditions and for each distance of movement from the starting point to the line in Experiment 2. Data from the three line lengths were merged. 

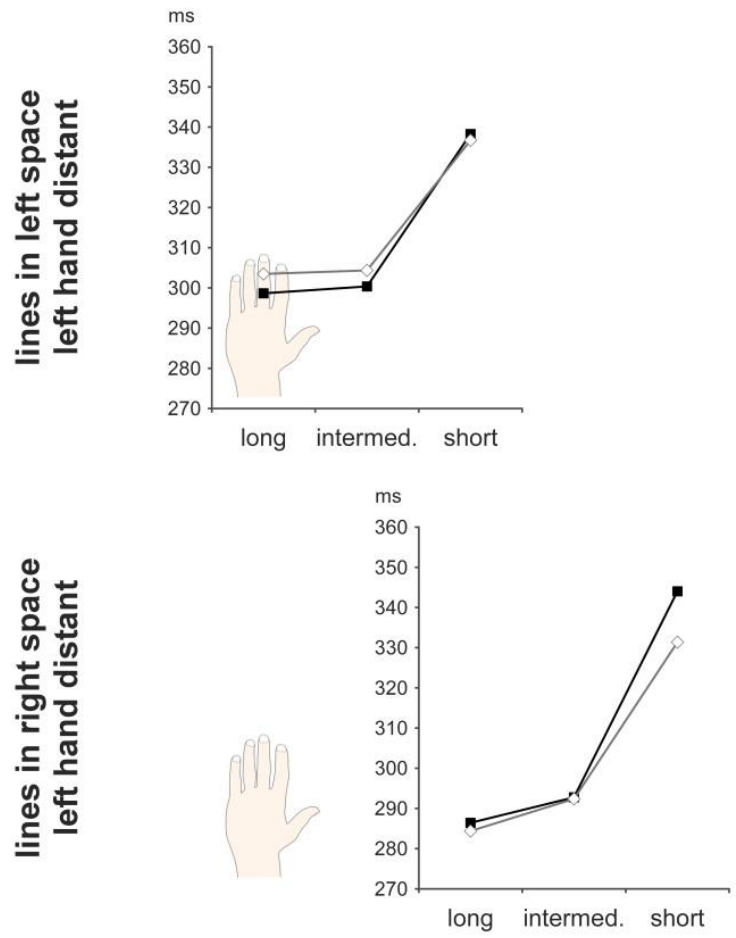

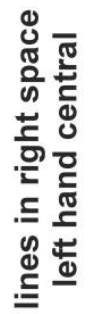

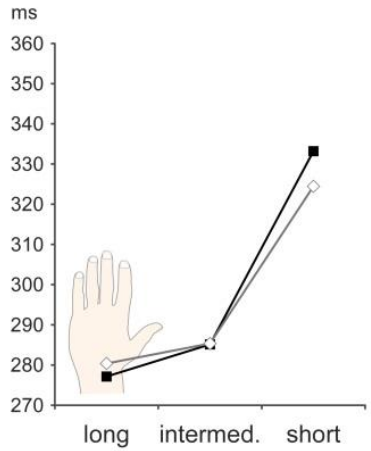

$\rightarrow$ visible

$\neg$ invisible

Figure 8. Mean movement initiation times (ms) from the ten participants for the six experimental conditions and for each distance of movement from the starting point to the line in Experiment 2. Data from the three line lengths were merged. 